\title{
Chemical Fungicides and Bacillus siamensis H30-3 against Fungal and Oomycete Pathogens Causing Soil-Borne Strawberry Diseases
}

\author{
Bo Reen Park ${ }^{1 \dagger}$, Hyun Jin Son ${ }^{1 \dagger}$, Jong Hyeob Park ${ }^{1}$, Eun Soo Kim ${ }^{1}$, Seong Jin Heo ${ }^{1}$, Hae Ree Youn ${ }^{1}$, \\ Young Mo Koo', A Yeong $\mathrm{Heo}^{2}$, Hyong Woo Choi ${ }^{2}$, Mee Kyung Sang ${ }^{3}$, Sang-Woo Lee', Sung Hwan Choi ${ }^{1}$, \\ and Jeum Kyu Hong (iD ${ }^{1 *}$ \\ ${ }^{1}$ Department of Horticultural Science, Gyeongnam National University of Science and Technology (GNTech), Jinju \\ 52725, Korea \\ ${ }^{2}$ Department of Plant Medicine, Andong National University, Andong 36729, Korea \\ ${ }^{3}$ National Institute of Agricultural Sciences, Rural Development Administration, Wanju 55365, Korea
}

(Received on December 28, 2020; Revised on January 13, 2021; Accepted on January 13, 2021)

Chemical and biological agents were evaluated to inhibit Colletotrichum fructicola, Phytophthora cactorum, and Lasiodiplodia theobromae causing strawberry diseases. Mycelial growths of $\boldsymbol{C}$. fructicola were gradually arrested by increasing concentrations of fungicides pyraclostrobin and iminoctadine tris (albesilate). $P$. cactorum and $L$. theobromae were more sensitive to pyraclostrobin compared to $C$. fructicola, but iminoctadine tris (albesilate) was not or less effective to limit $P$. cactorum or $L$. theobromae, respectively. Bacillus siamensis H30-3 was antagonistic against the three pathogens by diffusible as well as volatile molecules, and evidently reduced aerial mycelial formation of $P$. cactorum. $B$. siamensis $\mathrm{H30-3}$ growth was declined by at least 0.025 $\mathrm{mg} / \mathrm{ml}$ of pyraclostrobin. The two fungicides additively inhibited mycelial growths of $C$. fructicola, but not of $P$. cactorum and $L$. theobromae. B. siamensis $\mathbf{H 3 0 - 3}$ volatiles led to less growth of $C$. fructicola than one reduced by the fungicides. Taken together, in vitro antimicrobial activities of the two fungicides together with or without

\footnotetext{
These authors contributed equally to this work.

*Corresponding author.

Phone) +82-55-751-3258, FAX) +82-55-751-3257

E-mail) jkhong@gntech.ac.kr

ORCID

Jeum Kyu Hong

https://orcid.org/0000-0002-9161-511X

(c) This is an Open Access article distributed under the terms of the Creative Commons Attribution Non-Commercial License (http:// creativecommons.org/licenses/by-nc/4.0) which permits unrestricted noncommercial use, distribution, and reproduction in any medium, provided the original work is properly cited.
}

Articles can be freely viewed online at www.ppjonline.org.
B. siamensis H30-3 volatiles may be cautiously incorporated into integrated management of strawberry diseases dependent on causal pathogens.

Keywords : antimicrobial, Bacillus siamensis, fungicides, strawberry diseases, volatiles

Handling Editor : Youn-Sig Kwak

Strawberry production worldwide is strained by Colletotrichum and Phytophthora species. Strawberry anthracnose by Colletotrichum spp. has been serious threat and various controls including chemical fungicides were suggested. C. fructicola is a part of C. gloeosporioides species complex, and DNA markers were developed to differentiate the fungal species from other Colletotrichum spp. causing strawberry anthracnose (Gan et al., 2017). Many Korean C. gloeosporioides isolates causing strawberry anthracnose was re-classified as $C$. fructicola (Nam et al., 2013). Fungicides azoxystrobin and prochloraz-Mn protected strawberry crown anthracnose by dipping the seedlings in fungicides before planting in fruit production fields (Kim et al., 2002; Nam et al., 2014). Control efficacies of azoxystrobin, pyraclostrobin and thiophanate-methyl as protectants were found in strawberry plant fields over 3 years against $C$. gloeosporioides-causing crown rot (MacKenzie et al., 2009). Phytophthora cactorum infection led to leather rot and crown rot of strawberry (Grove et al., 1985; Lim et al., 1998; Madden et al., 1991). Azoxystrobin, mefenoxam, and pyraclostrobin showed protectively controlled strawberry leather rot, whilst postinfection treatment with mefenoxam only decreased the 
leather rot (Rebollar-Alviter et al., 2007). Metalaxyl and fosetyl-Al reduced the leather rot by foliar-spraying and soil-drenching in strawberry fruit production fields (Ellis et al., 1998). In South Korea, two and six fungicides were registered to control Phytophthora rot in strawberry nursery and fruit production fields, respectively, in 2020. However, pyraclostrobin and iminoctadine tris (albesilate) were not investigated for the strawberry Phytophthora rot yet.

Lasiodiplodia theobromae infects many plants such as grapevine, mango, and peach trees (Burruano et al., 2008; Li et al., 2014; Saeed et al., 2017; Úrbez-Torres et al., 2008). Strawberry dieback by $L$. theobromae was reported in nursery of South Korea and fruit production fields in Turkey (Nam et al., 2016; Yildiz et al., 2014). Strawberry cv. 'Seolhyang', planted over $80 \%$ of production fields in South Korea, was highly susceptible to the dieback, which can be a great concern (Nam et al., 2016). Unfortunately, appropriate controls have not been demonstrated for the strawberry dieback.

Pyraclostrobin controlled anthracnose on strawberry, bean, grape, and pepper plants (Conner et al., 2004; Gao et al., 2017; Samuelian et al., 2014; Turechek et al., 2006). However, recent occurrences of pyraclostrobin-resistant $C$. acutatum isolates in pepper and strawberry fields warned of frequently using pyraclostrobin (Forcelini et al., 2016; Kim et al., 2019). Iminoctadine tris (albesilate) has shown in vitro antifungal activity against Alternaria dauci causing carrot Alternaria leaf spot and Aspergillus tubingensis causing Shine Muscat bunch rot (Do et al., 2020; Kim et al., 2020), and protectively and curatively reduced cucumber leaf spots by Corynespora cassiicola (Zhu et al., 2019). Iminoctadine tris (albesilate) was registered for strawberry anthracnose and grey mould in South Korea, but hardly demonstrated for other strawberry diseases.

Antagonistic microbes have controlled strawberry diseases. Endophytic bacterium Azospirillum brasilense REC3 in strawberry roots promoted plant growth as well as controlled anthracnose via enhanced plant immunity including augmented phenolics and pathogenesis-related gene expressions in plants (Tortora et al., 2012). Decreased anthracnose by Bacillus amyloliquefaciens S13-3 derived from soil was closely related with the bacterium-produced antimicrobial lipopeptides (Mochizuki et al., 2012; Yamamoto et al., 2015). Dipping strawberry roots in Trichoder$m a$ harzianum and $T$. viride conidial suspensions decreased leather rot (Porras et al., 2007). Pseudomonas fluorescence F113 and Serratia plymuthica HRO-C48 from rhizosphere of sugar beet and oilseed rape plants, respectively, reduced the strawberry root rot (Barahona et al., 2011; Kurze et al., 2001).
Bacillus siamensis H30-3 promoted Chinese cabbage plant growth under normal ambient and adverse environments like high temperature- and high temperaturedrought stresses (Lee et al., 2018; Shin et al., 2019). B. siamensis H30-3 was antagonistic to Alternaria brassicicola and Colletotrichum higginsianum causing black spot and anthracnose diseases in Chinese cabbage, respectively, but diseases by $A$. brassicicola and $C$. higginsianum were reduced in cv. Ryeokgwang, not cv. Buram-3-ho (Lee et al., 2018). Chinese cabbage soft rot by Pectobacterium carotovorum subsp. carotovorum was alleviated by B. siamensis H30-3 (Shin et al., 2019). These results indicate that $B$. siamensis $\mathrm{H} 30-3$ has broad antimicrobial activities against fungi and bacteria.

In this study, in vitro antifungal activities of two fungicides pyraclostrobin and iminoctadine tris (albesilate) were demonstrated against $C$. fructicola, $P$. cactorum, and $L$. theobromae by singly or simultaneously. $B$. siamensis H30-3 was applied to the three pathogens to investigate whether the bacterial strain arrests the pathogen growths through diffusible and volatile antifungal machineries. Tolerance of $B$. siamensis $\mathrm{H} 30-3$ to the two fungicides was evaluated for simultaneous usage potentials with chemical controls for integrated strawberry disease management. Simultaneous treatment with two fungicides with or without B. siamensis $\mathrm{H} 30-3$ volatiles on the three pathogen growths was also investigated.

In vitro antimicrobial activities of pyraclostrobin and iminoctadine tris (albesilate) were evaluated against $C$. fructicola, P. cactorum, and L. theobromae (Fig. 1). Colony formation (Fig. 1A) and mycelial growths (Fig. 1B) of C. fructicola were gradually decreased by increasing pyraclostrobin $(0,0.00625,0.0125,0.025,0.05$, and $0.1 \mathrm{mg} / \mathrm{ml})$ and iminoctadine tris (albesilate) $(0,0.00625,0.0125,0.025$, 0.05 , and $1 \mu \mathrm{g} / \mathrm{ml}$ ). Linear repression analyses demonstrated strong correlation of fungicides concentrations with reduced growths of $C$. fructicola, shown by increasing concentrations of pyraclostrobin $\left(\mathrm{Y}=-14.79 \mathrm{X}+100.59, R^{2}=\right.$ $0.8943)$ and iminoctadine tris (albesilate) $(\mathrm{Y}=-17.308 \mathrm{X}+$ $123.71, R^{2}=0.9689$ ).

Increasing pyraclostrobin concentrations at 0.00625 , $0.0125,0.025,0.05$, and $0.1 \mathrm{mg} / \mathrm{ml}$ resulted in significant decreases in mycelial growth of $C$. fructicola to ca. $56.9 \%$, $50.2 \%, 42.5 \%, 28.3 \%$, and $15.2 \%$ compared to mock-treated control. Same dosage range of pyraclostrobin showed more drastic suppressions in mycelial growths of $P$. cactorum and L. theobromae. Minimal concentration of 0.00625 $\mathrm{mg} / \mathrm{ml}$ of pyraclostrobin reduced growth of $P$. cactorum and $L$. theobromae by ca. $18.9 \%$ and $17.5 \%$, respectively. More doses of pyraclostrobin to $0.1 \mathrm{mg} / \mathrm{ml}$ did not change $P$. 


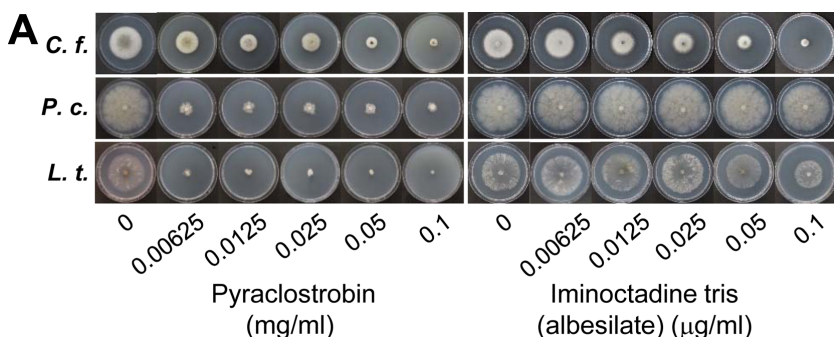

B

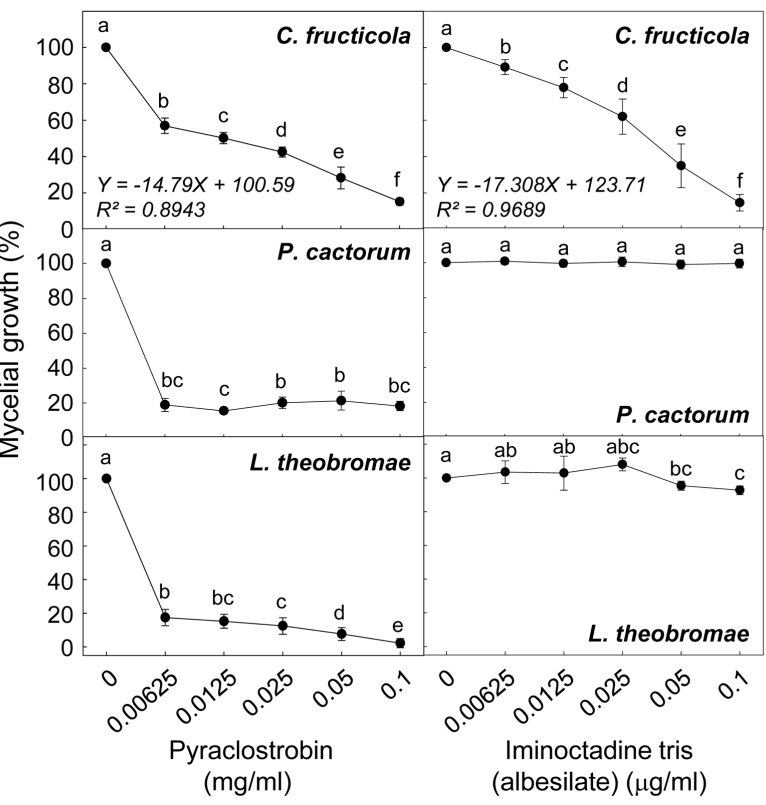

Fig. 1. In vitro inhibitory efficacies of two chemical fungicides pyraclostrobin and iminoctadine tris (albesilate) on mycelial growths of Colletotrichum fructicola isolate SAn-3, Phytophthora cactorum isolate P-9815 (KACC 40183) and Lasiodiplodia theobromae isolate LT120902. (A) Colony formations of C. fructicola, P. cactorum, and $L$. theobromae on 1/2-potato dextrose agar media containing different concentrations of pyraclostrobin and iminoctadine tris (albesilate), and cultured at $25^{\circ} \mathrm{C}$ for 5, 10, and 2 days for C. fructicola, P. cactorum, and $L$. theobromae, respectively. (B) Relative mycelial growths (\%) of C. fructicola, P. cactorum, and L. theobromae. Bars represent the standard errors of the means of the five independent experimental replications. Each experiment has four replications. Means followed by the same letters are not significantly different at 5\% level by least significant difference test.

cactorum suppression efficacy, whilst increasing doses to more than 0.025 to $0.1 \mathrm{mg} / \mathrm{ml}$ gradually more suppressed the growths of $L$. theobromae. Increasing iminoctadine tris (albesilate) concentrations at $0.00625,0.0125,0.025,0.05$, and $0.1 \mu \mathrm{g} / \mathrm{ml}$ led to significant decreases in growth of $C$. fructicola to ca. $89.2 \%, 78.0 \%, 62.0 \%, 34.9 \%$, and $14.6 \%$ compared to mock-treated control. Same dosage ranges of iminoctadine tris (albesilate) has no antimicrobial activity against $P$. cactorum, and only slightly reduced growth in-
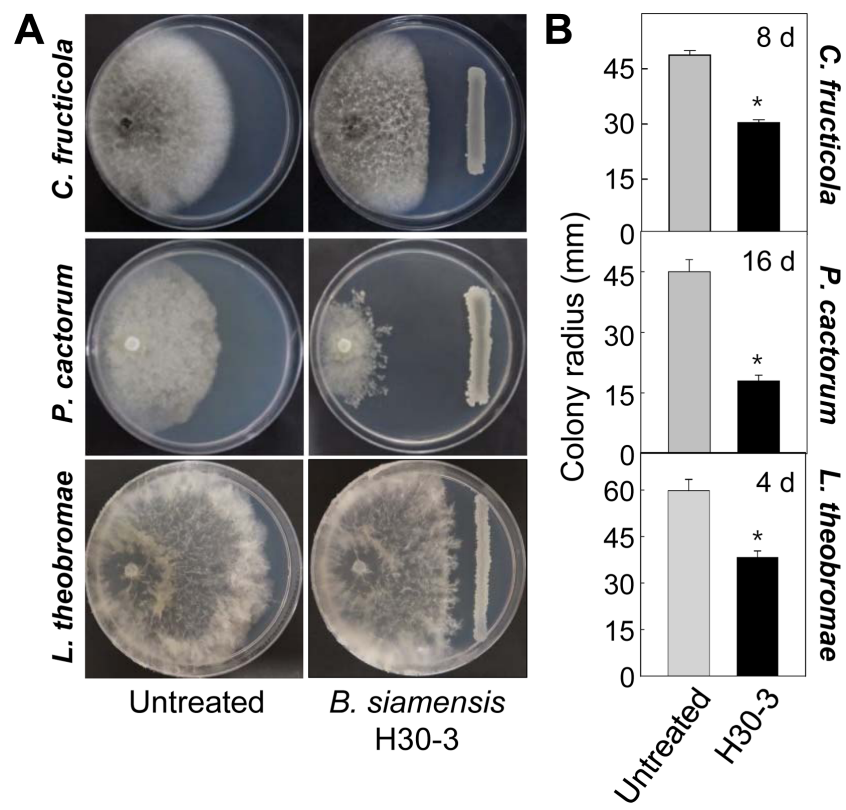

Fig. 2. In vitro inhibition of mycelial growths of Colletotrichum fructicola, Phytophthora cactorum, and Lasiodiplodia theobromae by dual cultures with Bacillus siamensis H30-3. (A) Mycelial cultures on 1/2-potato dextrose agar media in the absence or presence of $B$. siamensis $\mathrm{H} 30-3$ co-culture at $25^{\circ} \mathrm{C}$. Photos were taken 8, 16, and 4 days after inoculation of $C$. fructicola, $P$. cactorum, and L. theobromae, respectively. (B) Inhibited mycelial growths shown by half of the colony diameter after co-culture. Bars represent the standard errors of the means of the five independent experimental replications. Each experiment has four replications. Asterisks indicate significant differences as determined by Student's $t$-test $(P<0.05)$.

hibition was found against $L$. theobromae by $0.05-0.1 \mu \mathrm{g} /$ $\mathrm{ml}$. These results suggest that pyraclostrobin can be applied to control both Phytophthora rot and dieback caused by $P$. cactorum and L. theobromae, respectively. Antimicrobial activities of iminoctadine tris (albesilate) by more than 0.1 $\mu \mathrm{g} / \mathrm{ml}$ remains investigated.

Bacterial suspension $\left(10^{8} \mathrm{cfu} / \mathrm{ml}\right)$ of $B$. siamensis $\mathrm{H} 30$ 3 and the three pathogens were co-inoculated on 1/2-potato dextrose agar (PDA) media as described previously (Lee et al., 2018). B. siamensis H30-3 showed diffusible antimicrobial activities against $C$. fructicola, $P$. cactorum, and L. theobromae during dual cultures (Fig. 2). Compared to each mock-treated control at 8,16 , and 4 days after the cultures, mycelial growths of $C$. fructicola, $P$. cactorum, and $L$. theobromae were markedly limited as cultured with B. siamensis H30-3 simultaneously (Fig. 2A). Significantly reduced colony radius of the three phytopathogens were shown in Fig. 2B. Volatiles from B. siamensis H30-3 cultured on different media exhibited in vitro antimicrobial 

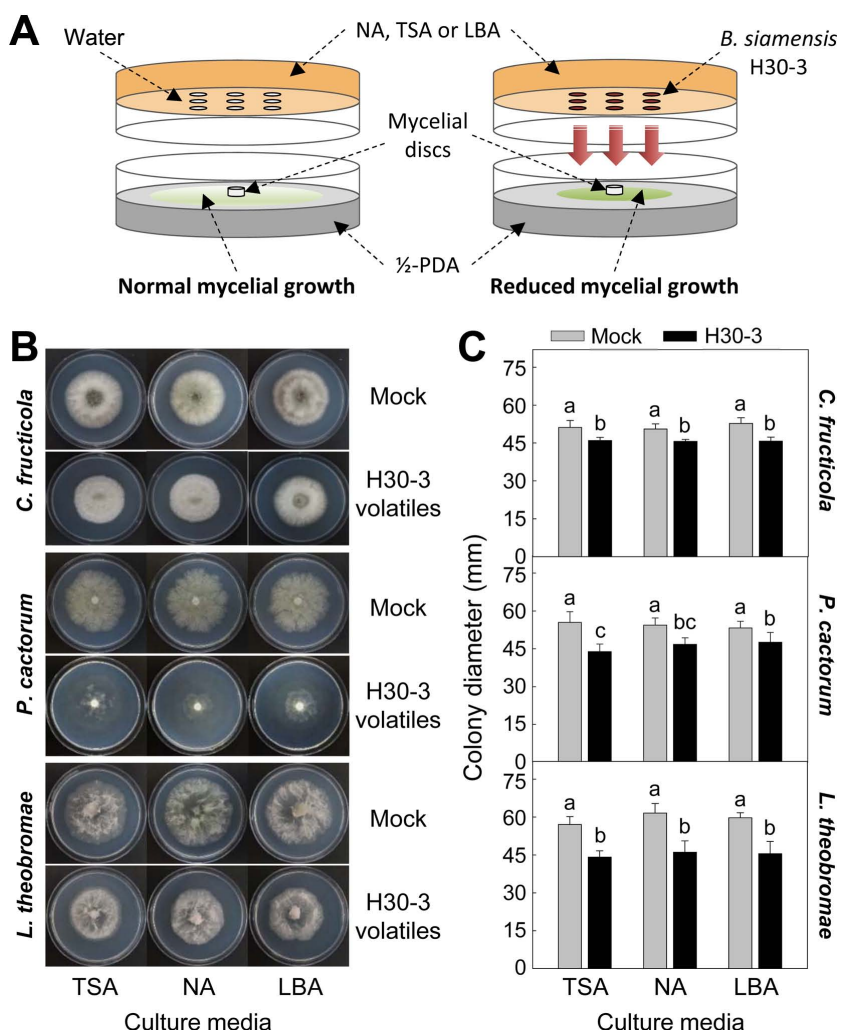

Fig. 3. In vitro inhibition of mycelial growths of Colletotrichum fructicola, Phytophthora cactorum, and Lasiodiplodia theobromae by Bacillus siamensis H30-3 volatiles. (A) Schematic diagram showing antimicrobial volatiles from $B$. siamensis H30-3 against phytopathogens. Nine drops (5 $\mu \mathrm{l}$ each) of $B$. siamensis $\mathrm{H} 30-3$ suspension $\left(10^{8} \mathrm{cfu} / \mathrm{ml}\right)$ were inoculated on tryptic soy agar (TSA), nutrient agar (NA), and Luria-Bertani agar (LBA). Arrows indicate releasing volatiles onto mycelia of the phytopathogens. (B) Pathogen cultures on 1/2-potato dextrose agar (PDA) media in the absence and presence of $B$. siamensis $\mathrm{H} 30-3$ volatiles on the three different growth media at $25^{\circ} \mathrm{C}$. Photos were taken 5,10 , and 2 days after inoculation of C. fructicola, P. cactorum, and L. theobromae, respectively. (C) Colony diameters (mm) of C. fructicola, P. cactorum, and $L$. theobromae treated with B. siamensis $\mathrm{H} 30-3$ volatiles. Bars represent the standard errors of the means of the six independent experimental replications. Each experiment has four replications. Asterisks indicate significant differences as determined by Student's $t$-test $(P<0.05)$.

activities against $C$. fructicola, $P$. cactorum and $L$. theobromae (Fig. 3). Volatiles from B. amyloliquefaciens, B. pumilus and $B$. velezensis strains showed antifungal activities against diverse fungal species (Asari et al. 2016; Lim et al., 2017; Morita et al., 2019). Reduced colonies of the three pathogens were found on 1/2-PDA media covered different culture media tryptic soy agar, nutrient agar, and LuriaBertani agar media drop-inoculated by B. siamensis $\mathrm{H} 30-$

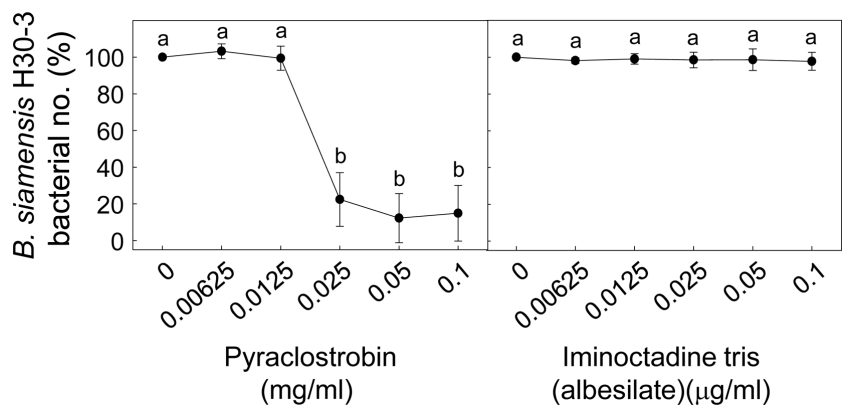

Fig. 4. Effects of pyraclostrobin and iminoctadine tris (albesilate) on in vitro growth of Bacillus siamensis $\mathrm{H} 30-3$. Bacterial suspensions in nutrient broth liquid media with or without different concentrations of the two fungicides were cultured and relative bacterial growths in response to the two fungicides were demonstrated as percentage (\%) compared to those in untreated culture. Values presented are means and error bars indicated the standard errors of the means of five independent experimental replications. Each experiment has four replications. Means followed by the same letters are not significantly different at $5 \%$ level by least significant difference test.

3 (Fig. 3A). Particularly, aerial mycelia of $P$. cactorum was drastically reduced by $B$. siamensis H30-3 volatiles. Distinct difference in growth inhibition by the different bacterial media was not found (Fig. 3B). B. siamensis H30-3 has several antimicrobial lipopeptide-encoding genes such as bacD, $b m y A$, ituA, and $\operatorname{srf} A$ (Lee et al., 2018), which may be involved in the suppressed $C$. fructicola, $P$. cactorum, and L. theobromae.

In vitro bactericidal activities of the two fungicides against B. siamensis H30-3 were investigated (Fig. 4). B. siamensis $\mathrm{H} 30-3\left(10^{5} \mathrm{cfu} / \mathrm{ml}\right)$ were initially cultured in 4-ml of nutrient broth with or without increasing concentrations of the two fungicides at $30^{\circ} \mathrm{C}$ for $24 \mathrm{~h}$ and the bacterial growths were evaluated spectrophotometrically at $\mathrm{OD}_{600}$ (Hong et al., 2016). Bacterial growth was declined by more than $0.025 \mathrm{mg} / \mathrm{ml}$ of pyraclostrobin and no change was found by increased doses $(0.05-0.1 \mathrm{mg} / \mathrm{ml})$. Iminoctadine tris (albesilate) doses from 0.00625 to $0.1 \mu \mathrm{g} / \mathrm{ml}$ has no antibacterial effect on $B$. siamensis $\mathrm{H} 30-3$. Bacillus spp. as biological control agents were suggested to be integrated into disease management with chemical fungicides (Jacobsen et al., 2004; Korsten et al., 1997; Lee et al., 2012). B. siamensis H30-3 can be considered for strawberry disease control with the two fungicides. However, use of less than $0.0125 \mathrm{mg} / \mathrm{ml}$ pyraclostrobin will be recommended to avoid its negative effect on the growth of $B$. siamensis H30-3 during their simultaneous application.

Antimicrobial effects of the two chemical fungicides with B. siamensis H30-3 volatiles were investigated (Fig. 


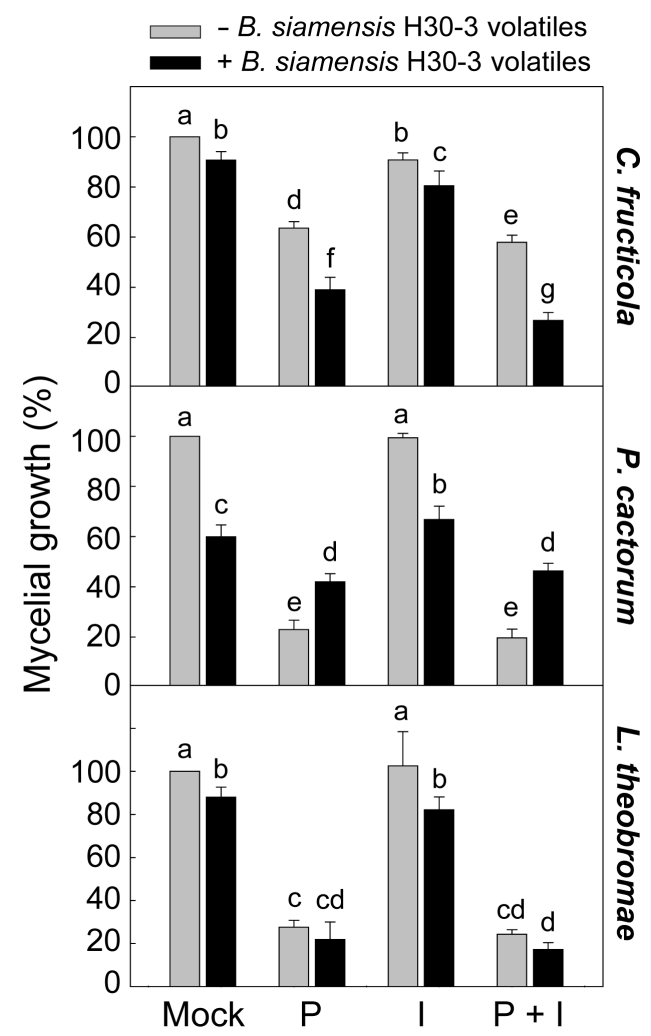

Fig. 5. Antimicrobial activities of chemical fungicides pyraclostrobin and iminoctadine tris (albesilate) with or without volatiles from Bacillus siamensis H30-3. Mycelial growths of Colletotrichum fructicola, Phytophthora cactorum and Lasiodiplodia theobromae on 1/2-potato dextrose agar (PDA) media supplemented with pyraclostrobin $(\mathrm{P})(0.00625 \mathrm{mg} / \mathrm{ml})$ and/or iminoctadine tris (albesilate) (I) $(0.00625 \mu \mathrm{g} / \mathrm{ml})$. The PDA media were covered by tryptic soy agar media inoculated by $B$. siamensis H30-3. Colony diameters were measured after cultures at $25^{\circ} \mathrm{C}$ for 5,10 , and 2 days for $C$. fructicola, $P$. cactorum and L. theobromae, respectively. Values presented are means and error bars indicated the standard errors of the means of five independent experimental replications. Each experiment has four replications. Means followed by the same letters are not significantly different at $5 \%$ level by least significant difference test.

5). Co-treatment with pyraclostrobin $(0.00625 \mathrm{mg} / \mathrm{ml})$ and iminoctadine tris (albesilate) $(0.00625 \mu \mathrm{g} / \mathrm{ml})$ without $B$. siamensis $\mathrm{H30-3}$ volatiles resulted in more significantly suppressed growths of $C$. fructicola compared to the one treated with single fungicide. However, $P$. cactorum and $L$. theobromae was not synergistically suppressed by the co-treatment with the two fungicides. Together with $B$. siamensis H30-3 volatiles, mycelial growths of $C$. fructicola were more efficiently decreased by pyraclostrobin and/or iminoctadine tris (albesilate). The fungicide-suppressed $P$. cactorum was rather relieved by $B$. siamensis $\mathrm{H} 30-3$ vola- tiles. No significant difference in growths of $L$. theobromae treated with the fungicides by $B$. siamensis $\mathrm{H} 30-3$ volatiles. It should be solved how $B$. siamensis H30-3 volatiles will apply to the strawberry growing fields. Identification of $B$. siamensis H30-3 volatile compounds and improved production of the antimicrobial volatile compounds may pave a way for more efficient and reliable biological control of strawberry diseases.

Taken together, fungicides pyraclostrobin and iminoctadine tris (albesilate) and B. siamensis H30-3 showed their antimicrobial activities against the $C$. fructicola, $P$. cactorum, and $L$. theobromae singly or in combination. Use of B. siamensis H30-3 volatiles with pyraclostrobin and/or iminoctadine tris (albesilate) can be a more useful for controlling strawberry anthracnose by $C$. fructicola. In planta disease control efficacies of the chemical and biological agents will provide more sustainable production of strawberry fruits.

\section{Conflicts of Interest}

No potential conflict of interest relevant to this article was reported.

\section{Acknowledgments}

This research was supported by Gyeongnam National University of Science and Technology (GNTech) Grant 2020 to Jeum Kyu Hong.

\section{References}

Asari, S., Matzén, S., Petersen, M. A., Bejai, S. and Meijer, J. 2016. Multiple effects of Bacillus amyloliquefaciens volatile compounds: plant growth promotion and growth inhibition of phytopathogens. FEMS Microbiol. Ecol. 92:fiw070.

Barahona, E., Navazo, A., Martínez-Granero, F., Zea-Bonilla, T., Pérez-Jiménez, R. M., Martín, M. and Rivilla, R. 2011. Pseudomonas fluorescence F113 mutant with enhanced competitive colonization ability and improved biocontrol activity against fungal root pathogens. Appl. Environ. Microbiol. 77:5412-5419.

Burruano, S., Mondello, V., Conigliaro, G., Alfonzo, A., Spagnolo, A. and Mugnai, L. 2008. Grapevine decline in Italy caused by Lasiodiplodia theobromae. Phytopathol. Mediterr. 47:132-136.

Conner, R. L., McAndrew, D. W., Kiehn, F. A., Chapman, S. R. and Froese, N. T. 2004. Effect of foliar fungicide application timing on the control of bean anthracnose in the navy bean 'Navigator'. Can. J. Plant Pathol. 26:299-303.

Do, J., Min, J., Kim, Y., Park, Y. and Kim, H. T. 2020. Detection of fungicidal activities against Alternaria dauci causing 
Alternaria leaf spot in carrot and monitoring for the fungicide resistance. Res. Plant Dis. 26:61-71 (in Korean).

Ellis, M. A., Wilcox, W. F. and Madden, L. V. 1998. Efficacy of metalaxyl, fosetyl-aluminum, and straw mulch for control of strawberry leather rot caused by Phytophthora cactorum. Plant Dis. 82:329-332.

Forcelini, B. B., Seijo, T. E., Amiri, A. and Peres, N. A. 2016. Resistance in strawberry isolates of Colletotrichum acutatum from Florida to quinone-outside inhibitor fungicides. Plant Dis. 100:2050-2056.

Gan, P., Nakata, N., Suzuki, T. and Shirasu, K. 2017. Markers to differentiate species of anthracnose fungi identity Colletotrichum fructicola as the predominant virulent species in strawberry plants in Chiba Prefecture of Japan. J. Gen. Plant Pathol. 83:14-22.

Gao, Y.-Y., He, L.-F., Li, B.-X., Mu, W., Lin, J. and Liu, F. 2017. Sensitivity of Colletotrichum acutatum to six fungicides and reduction in incidence and severity of chili anthracnose using pyraclostrobin. Australs. Plant Pathol. 46:521-528.

Grove, G. G., Madden, L. V., Ellis, M. A. and Schmitthenner, A. F. 1985. Influence of temperature and wetness duration on infection of immature strawberry fruit by Phytophthora cactorum. Phytopathology 75:165-169.

Hong, J. K., Kim, H. J., Jung, H., Yang, H. J., Kim, D. H., Sung, C. H., Park, C.-J. and Chang, S. W. 2016. Differential control efficacies of vitamin treatments against bacterial wilt and grey mould diseases in tomato plants. Plant Pathol. J. 32:469-480.

Jacobsen, B. J., Zidack, N. K. and Larson, B. J. 2004. The role of Bacillus-based biological control agents in integrated pest management systems: plant diseases. Phytopathology 94:1272-1275.

Kim, S.-H., Choi, S.-Y., Lim, Y.-S., Yoon, J.-T. and Choi, B.S. 2002. Effect of chemical treatment on the control of strawberry anthracnose caused by Colletotrichum sp. Res. Plant Dis. 8:50-54 (in Korean).

Kim, S., Min, J. and Kim, H. T. 2019. Occurrence and mechanism of fungicide resistance in Colletotrichum acutatum causing pepper anthracnose against pyraclostrobin. Korean J. Pestic. Sci. 23:202-211 (in Korean).

Kim, Y. S., Kwon, H. T., Hong, S.-B. and Jeon, Y. 2020. Occurrence of bunch rot disease caused by Aspergillus tubingensis on Shine Muscat grape. Res. Plant Dis. 25:220225 (in Korean).

Korsten, L., De Villiers, E. E., Wehner, F. C. and Kotzé, J. M. 1997. Field sprays of Bacillus subtilis and fungicides for control of preharvest fruit diseases of avocado in South Africa. Plant Dis. 81:455-459.

Kurze, S., Bahl, H., Dahl, R. and Berg, G. 2001. Biological control of fungal strawberry diseases by Serratia plymuthica HRO-C48. Plant Dis. 85:529-534.

Lee, Y. H., Cho, Y.-S., Lee, S. W. and Hong, J. K. 2012. Chemical and biological controls of balloon flower stem rots caused by Rhizoctonia solani and Sclerotinia sclerotiorum. Plant Pathol. J. 28:156-163.
Lee, Y. H., Jang, S. J., Han, J.-H., Bae, J. S., Shin, H., Park, H. J., Sang, M. K., Han, S. H., Kim, K. S., Han, S.-W. and Hong, J. K. 2018. Enhanced tolerance of Chinese cabbage seedlings mediated by Bacillus aryabhattai $\mathrm{H} 26-2$ and B. siamensis H30-3 against high temperature stress and fungal infections. Plant Pathol. J. 34:555-566.

Li, Z., Wang, Y.-T., Gao, L., Wang, F., Ye, J.-L. and Li, G.-H. 2014. Biochemical changes and defence responses during the development of peach gummosis caused by Lasiodiplodia theobromae. Eur. J. Plant Pathol. 138:195-207.

Lim, S. M., Yoon, M.-Y., Choi, G. J., Choi, Y. H., Jang, K. S., Shin, T. S., Park, H. W., Yu, N. H., Kim, Y. H. and Kim, J.-C. 2017. Diffusible and volatile antifungal compounds produced by an antagonistic Bacillus velezensis G341 against various phytopathogenic fungi. Plant Pathol. J. 33:488-498.

Lim, Y.-S., Jung, K.-C., Kim, S.-H. and Bark, S.-D. 1998. Crown rot of strawberry (Fragaria ananassa) caused by Phytophthora cactorum. Korean J. Plant Pathol. 14:753-737.

MacKenzie, S. J., Mertely, J. C. and Peres, N. A. 2009. Curative and protectant activity of fungicides for control of crown rot of strawberry caused by Colletotrichum gloeosporioides. Plant Dis. 93:815-820.

Madden, L. V., Ellis, M. A., Grove, G. G., Reynolds, K. M. and Wilson, L. L. 1991. Epidemiology and control of leather rot of strawberries. Plant Dis. 75:439-446.

Mochizuki, M., Yamamoto, S., Aoki, Y. and Suzuki, S. 2012. Isolation and characterization of Bacillus amyloliquefaciens S13-3 as a biological control agent for anthracnose caused by Colletotrichum gloeosporioides. Biocontrol Sci. Technol. 22:697-709.

Morita, T., Tanaka, I., Ryuda, N., Ikari, M., Ueno, D. and Someya, T. 2019. Antifungal spectrum characterization and identification of strong volatile organic compounds produced by Bacillus pumilus TM-R. Heliyon 5:e01817.

Nam, M. H., Lee, I. H. and Kim, H. G. 2014. Dipping strawberry plants in fungicides before planting to control anthracnose. Res. Plant Dis. 20:54-58 (in Korean).

Nam, M. H., Park, M. S., Kim, H. S., Kim, T. I., Lee, E. M., Park, J. D. and Kim, H. G. 2016. First report of dieback caused by Lasiodiplodia theobromae in strawberry plants in Korea. Mycobiology 44:319-324.

Nam, M. H., Park, M. S., Lee, H. D. and Yu, S. H. 2013. Taxonomic re-evaluation of Colletotrichum gloeosporioides isolated from strawberry in Korea. Plant Pathol. J. 29:317322.

Porras, M., Barrau, C., Arroyo, F. T., Santos, B., Blanco, C. and Romero, F. 2007. Reduction of Phytophthora cactorum in strawberry fields by Trichoderma spp. and soil solarization. Plant Dis. 91:142-146.

Rebollar-Alviter, A., Madden, L. V. and Ellis, M. A. 2007. Preand post-infection activity of azoxystrobin, pyraclostrobin, mefenoxam, and phosphite against leather rot of strawberry, caused by Phytophthora cactorum. Plant Dis. 91:559-564.

Saeed, E. E., Sham, A., AbuZarqa, A., Al Shurafa, K. A., Al 
Naqbi, T. S., Iratni, R., El-Tarabily, K. and AbuQamar, S. F. 2017. Detection and management of mango dieback disease in the United Arab Emirates. Int. J. Mol. Sci. 18:2086.

Samuelian, S. K., Greer, L. A., Savocchia, S. and Steel, C. C. 2014. Application of Cabrio (a.i. pyraclostrobin) at flowering and veraison reduces the severity of bitter rot (Greeneria uvicola) and ripe rot (Colletotrichum acutatum) of grapes. Aust. J. Grape Wine Res. 20:292-298.

Shin, D. J., Yoo, S.-J., Hong, J. K., Weon, H.-Y., Song, J. and Sang, M. K. 2019. Effect of Bacillus aryabhattai H26-2 and $B$. siamensis $\mathrm{H} 30-3$ on growth promotion and alleviation of heat and drought stresses in Chinese cabbage. Plant Pathol. J. 35:178-187.

Tortora, M. L., Díaz-Ricci, J. C. and Pedraza, R. O. 2012. Production of strawberry plants (Fragaria ananassa Duch.) against anthracnose disease induced by Azospirillum brasilense. Plant Soil 356:279-290.

Turechek, W. W., Peres, N. A. and Werner, N. A. 2006. Pre- and post-infection activity of pyraclostrobin for control of an- thracnose fruit rot of strawberry caused by Colletotrichum acutatum. Plant Dis. 90:862-868.

Úrbez-Torres, J. R., Leavitt, G. M., Guerrero, J. C., Guevara, J. and Gubler, W. D. 2008. Identification and pathogenicity of Lasiodiplodia theobromae and Diplodia seriata, the causal agents of bot canker disease of grapevines in Mexico. Plant Dis. 92:519-529.

Yamamoto, S., Shiraishi, S. and Suzuki, S. 2015. Are cyclic lipopeptides produced by Bacillus amyloliquefaciens S13-3 responsible for the plant defence response in strawberry against Colletotrichum gloeosporioides? Lett. Appl. Microbiol. 60:379-386.

Yildiz, A., Benlioglu, K. and Benlioglu, H. S. 2014. First report of strawberry dieback caused by Lasiodiplodia theobromae. Plant Dis. 98:1579.

Zhu, J., Zhang, L., Ma, D., Gao, Y., Mu, W. and Liu, F. 2019. A bioactivity and biochemical analysis of iminoctadine tris (albesilate) as a fungicide against Corynespora cassiicola. Pestic. Biochem. Physiol. 158:121-127. 